Research paper

\title{
Intensity of sulfonitric treatment on multiwall carbon nanotubes
}

\author{
Sofía Gómez ${ }^{\mathrm{a}, *}$, Nicolás M. Rendtorff ${ }^{\mathrm{a}, \mathrm{b}}$, Esteban F. Aglietti ${ }^{\mathrm{a}, \mathrm{b}}$, Yoshio Sakka ${ }^{\mathrm{c}}$, Gustavo Suarez ${ }^{\mathrm{a}, \mathrm{b}}$ \\ a Centro de Tecnología de Recursos Minerales y Cerámica (CETMIC), Camino Centenario y 506, M.B. Gonnet C.C.49 (B1897ZCA), Argentina \\ ${ }^{\mathrm{b}}$ Departamento de Química, Facultad de Ciencias Exactas- UNLP, Calle 115 y 47, La Plata 1900, Argentina \\ ${ }^{\mathrm{c}}$ National Institute for Materials Science (NIMS), Tsukuba, Ibaraki 305-0047, Japan
}

\section{A R T I C L E I N F O}

Article history:

Received 23 June 2017

In final form 8 October 2017

Available online 10 October 2017

\section{Keywords:}

Carbon nanotubes

Sulfonitric treatment

Surface characterization

Treatment temperature

\begin{abstract}
A B S T R A C T
We present a study of sulfonitric treatment and its effect on MWCNTs at different temperatures $(90,110$, 130 and $150^{\circ} \mathrm{C}$ ) using DRX, XPS, FTIR, Raman spectroscopy, TEM and zeta potential. It was found that oxidation starts with the $\mathrm{C}-\mathrm{C}$ and $\mathrm{C}-\mathrm{H}$ bonds generating different oxidized groups from alcohol to carboxylic acid, following a sequential oxidation. Given that heterocoagulation needs a maximum zeta potential gap between the ceramic and the MWCNT surface and it significantly exist a risk of manipulate acids at high temperature it is recommended to use acid treatment of $\mathrm{CNT}$ at $110^{\circ} \mathrm{C}$ for generating ceramic composites by heterocoagulation.
\end{abstract}

(ㄷ) 2017 Elsevier B.V. All rights reserved.

\section{Introduction}

Due to their unique mechanical, electrical and chemical properties carbon nanotubes have prompted a wide variety of potential applications in electronic, mechanical and optical devices [1-4]. Multiwall carbon nanotubes (MWCNTs) were the object of study of many researchers for many years with the aim of producing reinforced ceramic matrices [5].

Water-based suspensions are difficult to prepare due to the surface characteristics of CNTs and this fact is a technical disadvantage in manufacturing homogeneous ceramic-MWCNT composites. These hollowed carbon fibers are hydrophobic and with low chemical reactivity, particularly when pristine MWCNTs maintain the graphene structure.

Functionalization of CNTs is used to make their surface more reactive in contact with a matrix that contains them increasing its application field. Chemical functionalization of multiwall carbon nanotubes aims to achieve good dispersion and distribution of them in the final material. The functionalization of graphene structures by oxidation form several functional groups containing oxygen such as carboxyl, carbonyl, ether, ketone and other groups that can form on the MWCNT surface [6-9].

It is known that dispersability will be improved by the development of oxidized species on the surface of these materials. In con-

\footnotetext{
* Corresponding author.

E-mail addresses: sofiagomez@cetmic.unlp.edu.ar (S. Gómez), rendtorff@cetmic. unlp.edu.ar (N.M. Rendtorff), eaglietti@cetmic.unlp.edu.ar (E.F. Aglietti), SAKKA Yoshio@nims.go.jp (Y. Sakka),gsuarez@cetmic.unlp.edu.ar (G. Suarez).
}

sequence, an oxidative treatment on the MWCNTs allows their use in the processing of ceramic composite materials.

By means of sulfonitric treatment, MWCNTs undergoes to some oxidative reactions converting the $\mathrm{sp}^{2}$ carbon-carbon bonds into oxidized $\mathrm{sp}^{3}$ ones on the surface and forming oxidized species. This effect can be observed by the increment in the negative zeta potential even at acid $\mathrm{pH}[10]$. Consequently, good dispersion in the slurry is obtained $[5,11,12]$.

Nanoscale defects on MWCNTs were presented by Yamamoto et al. [13]. They use an acid treatment in order to improve the connectivity between the tubes and the ceramic matrix which will lead to a mechanical interlock improving the final mechanical properties. The aim of the acid treatment is to generate nanoscale defects and increase the negatively charged functional groups on the MWCNT terminals as well as along their extensions.

Some other authors worked with different temperatures and diverse treatment times. In this way Zhou et al. [10] studied the control of nanodefects in multiwalled carbon nanotubes by acid treatment searching for the optimal treatment time that would result in an effective number of nanodefects and a uniform dispensability. In this work, the authors demonstrated the existence of these nanodefects by TEM observations, Raman spectroscopy and FTIR measurements.

The acid treatments on MWCNTs and its applications have been reported in many works, but few of them have analyzed the relationship between the treatment conditions, the formation of the specific oxidized species on the surface and the creation of the nanodefects.

In a previous work we studied the acid treatment at $90{ }^{\circ} \mathrm{C}$ [14]. In this work, in order to compare and determine the acid treatment 
effect on the surface and the influence of the temperature of acid treatment, MWCNT oxidation at $90,110,130$ and $150{ }^{\circ} \mathrm{C}$ was studied. For this, we assumed that the treatment temperature is directly correlated to the oxidizing intensity. The techniques used for MWCNT characterization were XPS (X-ray photoelectron spectroscopy), FTIR (Fourier transform infrared spectroscopy), XRD (X-ray diffraction), Raman spectroscopy, TEM (transmission electron microscopy) and zeta potential.

It was found that functionalized MWCNTs are different from the original ones. Moreover, differences in the amount of oxidized species in samples treated at different temperatures were observed. Wall damage after treatment was also observed by transmission electron microscope (TEM).

\section{Material and methods}

MWCNTs produced by catalytic chemical vapor deposition (Bussan Nanotech, Ibaraki, Japan; diameter 20-70 nm) were used. A weight of $1.25 \mathrm{~g}$ of them was treated with a mixture of $\mathrm{H}_{2} \mathrm{SO}_{4}$ $98 \%$ and $\mathrm{HNO}_{3} 65 \%(3: 1 \mathrm{v} / \mathrm{v})$ for $20 \mathrm{~min}$. The treatment temperatures were $90,110,130$ and $150^{\circ} \mathrm{C}$. Samples treated at different temperatures were denominated T90, T110, T130 and T150 respectively. The oxidative agent produced by the sulfonitric mixture was described in a previous work [14]. The mixtures were cooled with water and washed up to $\mathrm{pH} \approx 7$. Finally they were dried, first at $60{ }^{\circ} \mathrm{C}$ ( 3 days) and then at $110^{\circ} \mathrm{C}$ until constant weight.

The crystallographic characterization was performed with X-ray diffraction equipment (Philips 3020). X-ray photoelectron spectroscopy was performed with an XR50, SPECS and a hemispheric energy analyzer PHOIBOS $100 \mathrm{MCD}$ with $\mathrm{Mg} \mathrm{K \alpha}(1253.6 \mathrm{eV})$ radiation, operating at $13 \mathrm{kV} 300 \mathrm{~W}$ in an energy fixed analyzer transmission (FAT) mode. To analyze the changes in the carbon nanotubes surface, infrared (FTIR) and Raman spectroscopy were used. For the FTIR spectra, IR-Bruker Vertex 70 in the wavelength range $500-4000 \mathrm{~cm}^{-1}$ was used. Raman Jobin Yvon Lab HRRaman at a wavelength of $\lambda=514.53 \mathrm{~nm}$ was used for Raman spectroscopy. The intensities were estimated as Lorentzian functions.

Zeta potentials were measured in deionized water, using a zeta potential analyzer (Zeta Plus, Zeta Potential, Brookhaven Instruments Corporation, USA) in the $3-11 \mathrm{pH}$ range. The $\mathrm{pH}$ value of the aqueous solution was adjusted with $\mathrm{HCl}$ and $\mathrm{NaOH}$.

MWCNTs were also characterized by transmission electron microscopy with a Zeiss EM109 Turbo microscope. A copper grid 200 mesh covered with a hydrophilic and acrylic membrane added with graphene was used.

\section{Results}

\subsection{XRD analysis}

Fig. 1 shows the XRD patterns of the pristine MWCNTs and treated samples. The main diffraction peak at $25.5^{\circ}(2 \theta)$ correspond to the $\left(\begin{array}{ll}0 & 02\end{array}\right)$ reflection of the hexagonal highly ordered graphite structure [15-18]. It was observed that for samples treated at 90, 110,130 and $150{ }^{\circ} \mathrm{C}$ this peak shifted slightly to lower angles. This indicated that the interlayer distance of graphite d002, was expanded due to the sulfate and nitrate ions intercalated into the coaxial graphene cylinders of MWCNTs [19].

As we reported in a previous work, the peak at $25.5^{\circ}(2 \theta)$ becomes smoother, indicating that the graphite structure of the treated MWCNTs was acid-oxidized without significant damage [14]. The other characteristic diffraction peaks are the typical of the graphite structure, the $C\left(\begin{array}{lll}1 & 0 & 0\end{array}\right)$ at $43^{\circ}$ and the $\mathrm{C}\left(\begin{array}{lll}0 & 0 & 4\end{array}\right)$ at $53^{\circ}$. The lack of three-dimensional graphene layers stacking in the nanotubes is the responsible for the absence of the $\left(\begin{array}{lll}1 & 0 & 1\end{array}\right)$ reflection.

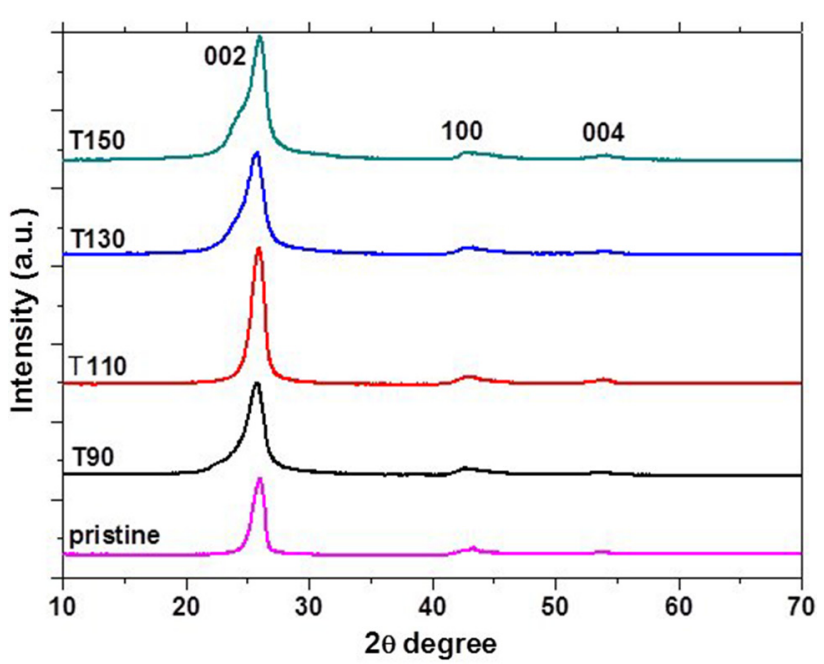

Fig. 1. XRD patterns of pristine and treated MWCNTs.

Because of the oxidized species formed on the nanotubes surface after acid treatment have non-crystalline nature they could not be detected by XRD. However, some differences can be observed. For samples T130 and T150, the presence of a shoulder in the left side of 002 graphite peak, at approximately $23.8^{\circ}$, can be observed. The thermal acid treatment could modify the distance between the planes, and this would lead to a peak shift towards smaller $2 \theta$ angles corresponding to a disorder graphene [20]. In spite of this effect, the position and intensity of the peaks are the same in all samples. No new crystalline species, salts or any other diffraction signals are present.

\subsection{XPS analysis}

Fig. 2 shows the XPS C1s spectra of pristine and treated MWCNT samples, mainly, carbon and oxygen species contents.

The XPS analysis and quantification results are shown in Table 1, which lists the possible band assignments and the atomic percentages of the oxidized species in the studied samples.

It is possible to see that in all the cases we found the same species, however intensities varies in each sample, although without correlation. During the manufacturing process some oxidized species could be formed and are observed in the pristine MWCNTs [21]. In all the cases the amount of carboxylic and carbonyl groups are a greater than in the treated MWCNTs ones.

Since the MWCNTs consist of rolled concentric layers the main bonds found are $\mathrm{C}-\mathrm{C}$ and $\mathrm{C}-\mathrm{H}$, as shown in Table 1 .

In all the treated samples the amount of $\mathrm{C}=\mathrm{O}$ (carboxyl and carbonyl groups) is larger with respect to the pristine ones, whereas $\mathrm{C}-\mathrm{OH}, \mathrm{C}-\mathrm{N}$ and $\mathrm{C}-\mathrm{O}-\mathrm{C}$ groups content decrease in treated samples. It is known that both sulfuric and nitric acids can oxidize $C$ from the CNT surface following a sequential oxidation. This process starts first with the $\mathrm{C}-\mathrm{C}$ and $\mathrm{C}-\mathrm{H}$ bonds generating different oxidized groups from alcohol to carboxylic. Furthermore nitric acid is responsible for the oxidized $\mathrm{C}-\mathrm{N}$ bonds. This behavior can be appreciated in Table 1 where the species percentages decrease to the right.

Using other temperatures in the acid treatment, Daoush and Hong found the same species listed in Table 1 [22].

It is noted that $\mathrm{C}-\mathrm{C}$ and $\mathrm{C}-\mathrm{H}$ group presence vary in each sample without a defined trend; also $\mathrm{C}-\mathrm{OH}, \mathrm{C}-\mathrm{N}, \mathrm{C}-\mathrm{O}-\mathrm{C}$ groups change their intensity from sample to sample. Besides, T130 contains the smaller percentage of $\mathrm{C}-\mathrm{C}$ and $\mathrm{C}-\mathrm{H}$ bonds, and the largest amount of $\mathrm{C}=\mathrm{O}$, indicating that the oxidation in this sample 

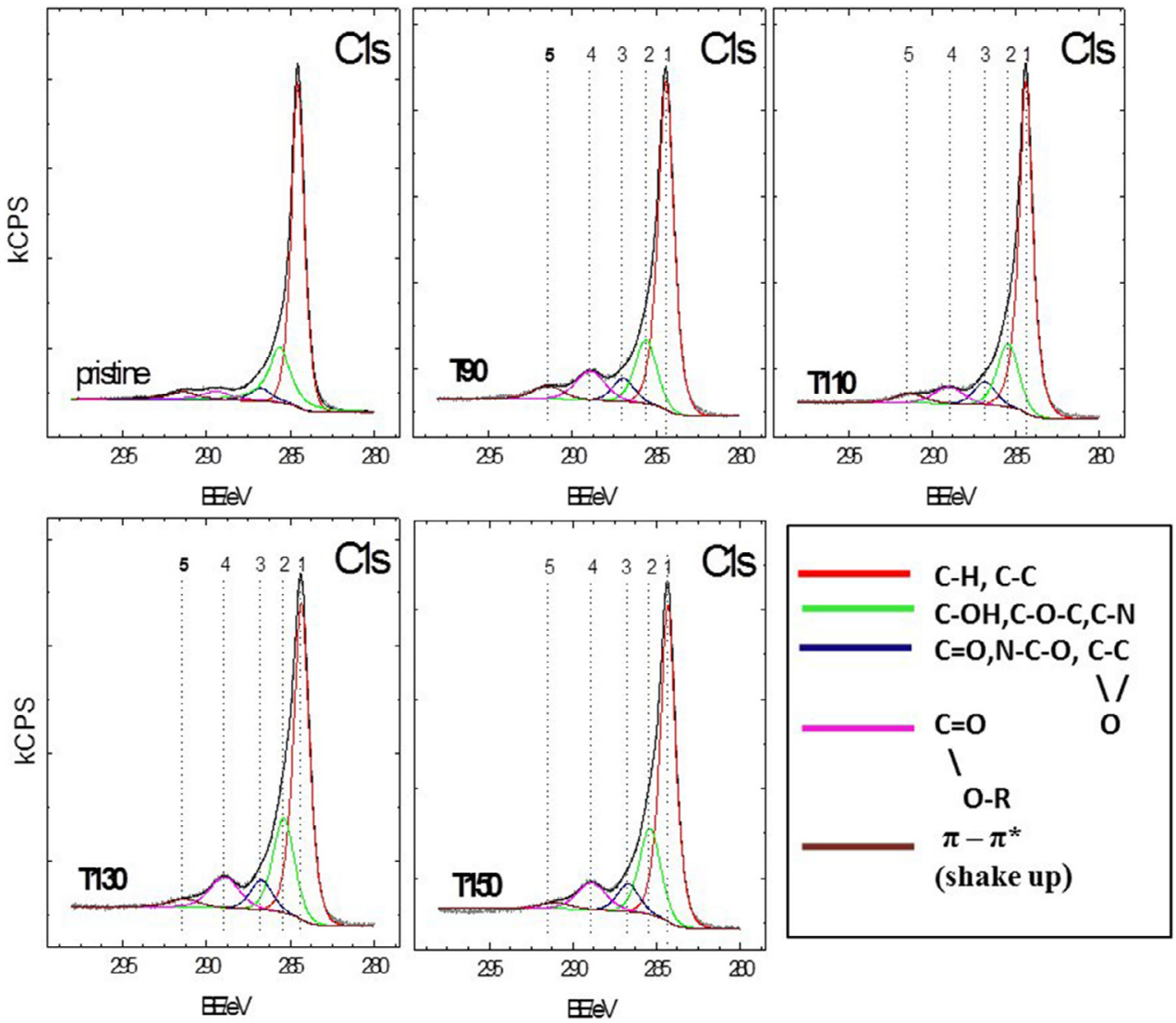

Fig. 2. $C 1 s$ spectra fitting into $C$ and $O$ chemical groups for the XPS spectra recorded for pristine and treated MWCNTs.

Table 1

Assignments of the C1s spectra fitting into $\mathrm{C}$ and $\mathrm{O}$ chemical groups for XPS spectra of pristine, T90, T110, T130 and T150 samples.

\begin{tabular}{|c|c|c|c|c|c|}
\hline Peak & 1 & 2 & 3 & 4 & 5 \\
\hline B.E./eV & 284.4 & 285.5 & 286.8 & 288.9 & 291.3 \\
\hline Bonds assignments & $\begin{array}{l}\mathrm{C}-\mathrm{C} \\
\mathrm{C}-\mathrm{H}\end{array}$ & $\begin{array}{c}\mathrm{C}-\mathrm{OH} \\
\mathrm{C}-\mathrm{N} \\
\mathrm{C}-\mathrm{O}-\mathrm{C}\end{array}$ & $\begin{array}{c}\mathrm{C}=\mathrm{O} \\
\mathrm{N}-\mathrm{C}-\mathrm{O} \\
\mathrm{C}-\mathrm{C}\end{array}$ & $\bigcup_{\mathrm{O}-\mathrm{R}}^{\mathrm{C}=\mathrm{O}}$ & $\begin{array}{l}\pi-\pi^{*} \\
\text { (shake } \\
\text { up) }\end{array}$ \\
\hline Pristine & $63.0 \%$ & $23.7 \%$ & $4.6 \%$ & $4.6 \%$ & $4.1 \%$ \\
\hline T90 & $63.9 \%$ & $16.1 \%$ & $5.8 \%$ & $9.9 \%$ & $4.3 \%$ \\
\hline T110 & $66.1 \%$ & $17.8 \%$ & $6.4 \%$ & $6.3 \%$ & $3.4 \%$ \\
\hline T130 & $57.9 \%$ & $22.6 \%$ & $7.1 \%$ & $10.0 \%$ & $2.4 \%$ \\
\hline T150 & $60.0 \%$ & $21.9 \%$ & $7.0 \%$ & $9.1 \%$ & $2.0 \%$ \\
\hline
\end{tabular}

is more aggressive than in the others, followed by those treated at $150{ }^{\circ} \mathrm{C}$.

Moreover, it can be observed that in T90 and T110 the percentage of $\mathrm{C}-\mathrm{C}$ and $\mathrm{C}-\mathrm{H}$ bonds increases. At the same time a decrease of the amount of $\mathrm{C}-\mathrm{OH}, \mathrm{C}-\mathrm{N}$ and $\mathrm{C}-\mathrm{O}-\mathrm{C}$ bonds was detected.

The results are difficult to compare analyzing the oxidized carbonyl and carboxylic groups because of the different process conditions, temperature, acid concentration and treatment time, but the degree of oxidation can be followed by the $\pi-\pi *$ (shake-up) transition showed in Fig. 3.

This shake-up peak of $C 1 \mathrm{~s}$, which is the characteristic peak of carbon nanotube, decreases with the treatment temperature. These results also indicate that the structure of carbon nanotube has been

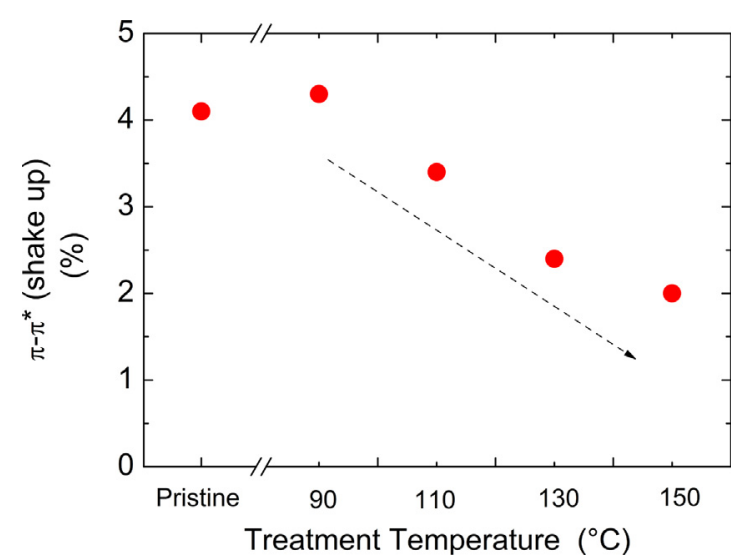

Fig. 3. Percentage of $\pi-\pi^{*}$ (shake-up) transition vs. treatment temperature.

changed and a new kind of carbon species, which does not contain conjugated $\pi$ bonds, is formed after carbon nanotube is acid treated. They also confirm the sequential oxidation increases the superficial damage in the CNTs which are affected by treatment temperature: in summary the higher the temperature, the higher the damage [23].

\subsection{FTIR surface characterization}

The FTIR spectra of pristine and oxidized at 90, 110, 130 and $150{ }^{\circ} \mathrm{C}$ MWCNTs are presented in Fig.4.

It is observed that pristine MWCNTs contain oxidized species. As already mentioned in section 3.2 it is possible that during the 


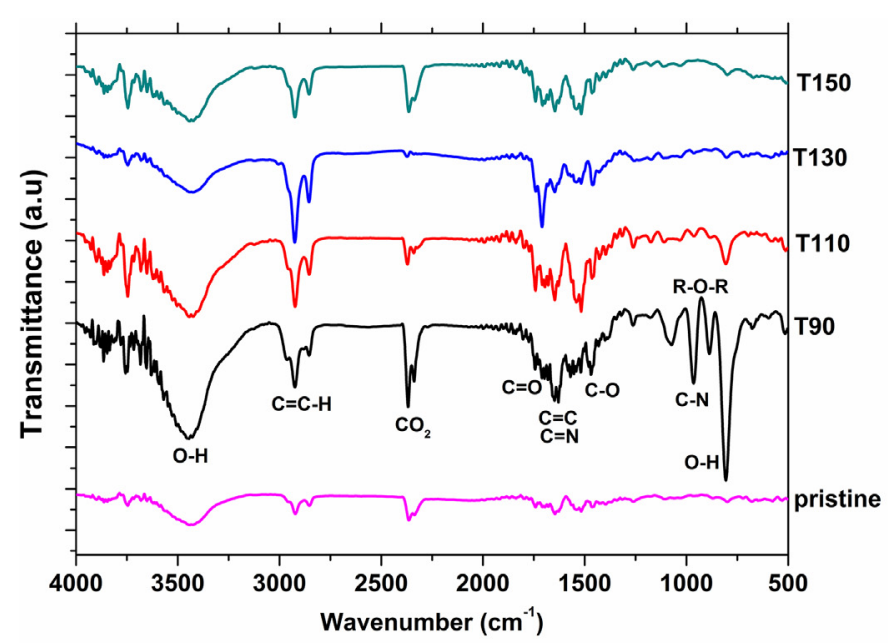

a)

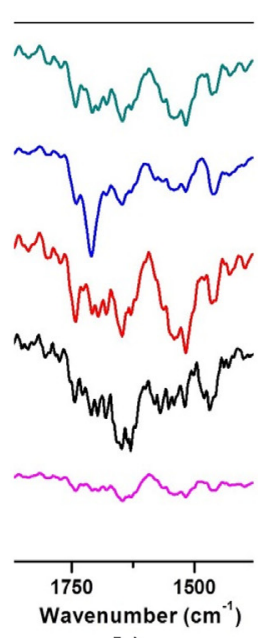

b)

Fig. 4. FTIR of pristine and treated MWCNTs.

manufacturing process oxidized species are formed. However, the amount of them is markedly lower than in the acid treated samples. This can be attributed to the fact that more oxidized species produce higher absorptions, observing more peaks and more intense (negatively) as shown in Fig. 4 [21,24].

The symmetric stretching of $\mathrm{C}-\mathrm{H}$ bonds is evidenced by the appearance of the band at $2949 \mathrm{~cm}^{-1}$. The band at $3500 \mathrm{~cm}^{-1}$ corresponds to the stretching vibrations of isolated surface $-\mathrm{OH}$ substituents and/or $-\mathrm{OH}$ of carboxyl groups and of adsorbed water. It could be noted that MWCNTs treated at $90{ }^{\circ} \mathrm{C}$ present some peaks larger (especially at $800 \mathrm{~cm}^{-1}$ ) than the others treated ones (corresponding to the $-\mathrm{OH}$ ). This can be attributed to water adsorbed on MWCNTs as the product of the appearance of polar groups, or simply phenolic groups.

In the range of $1750-1550 \mathrm{~cm}^{-1}, \mathrm{C}=\mathrm{O}$ and $\mathrm{C}=\mathrm{C}$ group bands would be located. At $1550 \mathrm{~cm}^{-1}$ a band due to aromatic and unsaturated the structural $C=C$ bonds can be seen. The presence of bands in $1300-950 \mathrm{~cm}^{-1}$ range is due to the existence of $\mathrm{C}-\mathrm{O}$ bonds coming from various chemical surroundings. The band at $2300 \mathrm{~cm}^{-1}$ comes from the absorbed $\mathrm{CO}_{2}$ during the test.

The band near $141 \mathrm{~cm}^{-1}$ can be assigned to the $\mathrm{C}-\mathrm{O}$ bond present in $\mathrm{C}-\mathrm{O}-\mathrm{C}$ groups containing oxygen bridges [14].

Also, at 1711 and $1638 \mathrm{~cm}^{-1}$, it can be seen the signals due to the vibrations of the $\mathrm{C}=0$ bonding, characteristic of carboxylic functional groups $(-\mathrm{COOH})$ and of ketone/quinine, respectively [25].

Although peaks of MWCNTs treated at different temperatures describe the same oxidized species, the intensity of peaks differs for each temperature. As we previously described, oxidation occurs sequentially and in parallel. That is, at first alcohols are formed then, as the case may be, oxidation will continue up to the carboxylic acids (via ketones and aldehydes). Those generated species prevent the agglomerate formation and promote compatibility among MWCNTs and other materials [14].

The $\mathrm{C}-\mathrm{N}$ bonds are evident by the presence of the band at 1244 $\mathrm{cm}^{-1}$, corresponding to the stretching of $\mathrm{C}-\mathrm{N}$ bonds $(\mathrm{vC}-\mathrm{N})$. The $\mathrm{N}$-atoms present in the graphitic lattice are evidenced by the $1580 \mathrm{~cm}^{-1}$ band which correspond to a mixed stretching mode of $\mathrm{C}=\mathrm{N}$ and $\mathrm{C}=\mathrm{C}(\mathrm{vC}=\mathrm{N}+\mathrm{C}=\mathrm{N})$. This value is slightly shifted to lower wavenumbers if compared with the signal from aromatic $\mathrm{C}=\mathrm{C}$ bonds but these results are in agreement with previous reports [26-29], which demonstrated that the replacement of carbon atoms with nitrogen atoms in the $\mathrm{sp} 2$ networks induces a strong
IR activity. Consequently, absorption in the $1200-1600 \mathrm{~cm}^{-1}$ regions would be expected if $\mathrm{N}$-atoms were covalently bonded to the carbon network [14].

Vibrations from alcohols, ether and presumably oxidative anhydride or carboxylic [30] are present at 1050 and $1300 \mathrm{~cm}^{-1}$ and correspond to the $\mathrm{C}-\mathrm{O}$ (and $-\mathrm{OH}$ ) products of the external graphite layers.

Fig. 4b shows the range of $2000-1200 \mathrm{~cm}^{-1}$. The same bands can be observed in the graphics from all of the treated MWCNTs. It could be observed that the intensity of the bands corresponding to $\mathrm{C}=\mathrm{O}$ and $\mathrm{C}-\mathrm{O}$ vary with the treatment temperature. These results are in concordance with XPS ones where it was found the same chemical species.

\subsection{Raman spectroscopy}

The pristine and treated MWCNTs were studied by Raman spectroscopy and the obtained spectra are shown in Fig.5. The characteristic Raman shift of the D and $G$ bands are present in all cases at $1360 \mathrm{~cm}^{-1}$, and $1590 \mathrm{~cm}^{-1}$ respectively between 1200 and 1800 $\mathrm{cm}^{-1}$. The D-band is caused by a double resonance scattering due to the presence of structural defects, while the G-band originates from tangential in-plane vibration of graphitic carbon atoms [31]. The high frequency shoulder of the G-band observed in Fig.5 is known as $\mathrm{D}^{\prime}$-band and frequently appears in MWCNT spectra [32]. Like the D-band, the $\mathrm{D}^{\prime}$-band is also a double-resonance one induced by disorder and defects.

In conclusion, the G-band is associated with the order and the D-band with the disorder of the graphite crystalline structure.

The position of the $G$ and $D$ bands are shown in Table 2 along with the calculated ratio between intensities, $\mathrm{I}_{\mathrm{D}} / \mathrm{I}_{\mathrm{G}}$. This ratio is directly related with the structure of the carbon material [33] and it can be used as a parameter to approximate the number of defects present on the MWCNT surface [34]. A high value of this ratio means defects on the carbon surface and low degree of graphitization [35]. Table 2 shows the $\mathrm{I}_{\mathrm{D}} / \mathrm{I}_{\mathrm{G}}$ ratio and it can be seen that the ratio increases considerably after the acid treatment. This can be correlated with a damage performed by acid attack, which is also observed by TEM, and described in Section 3.6.

An acid treatment at $120^{\circ} \mathrm{C}$ varying the time and the $\mathrm{HNO}_{3}$ proportion was studied by Motchelaho et al. [24] where the treatment effect on the surface damage is followed with TEM and Raman spectroscopy. The $I_{D} / I_{G}$ ratio was also higher for the treated 


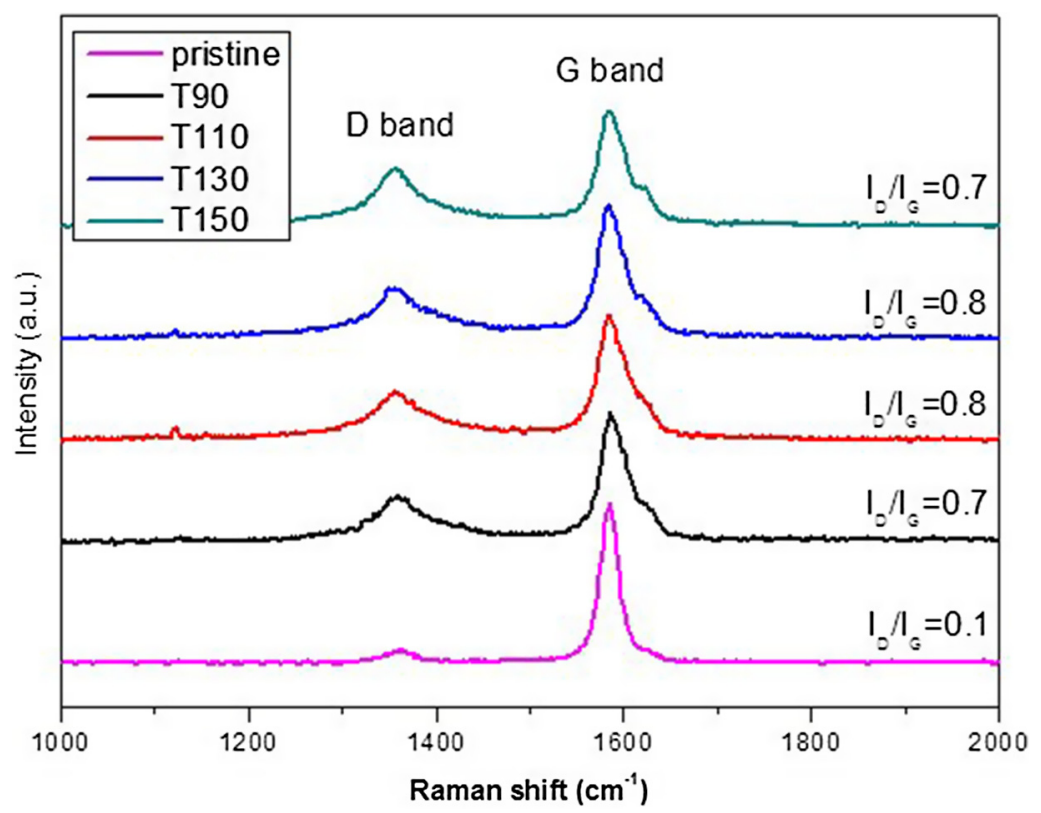

Fig. 5. Raman spectra of the pristine and treated MWCNTs.

Table 2

Position of the $G$ and $D$ bands, as well as the ratio between intensities $I_{D} / I_{G}$ for pristine and treated MWCNTs at different temperatures.

\begin{tabular}{|c|c|c|c|}
\hline & \multicolumn{2}{|c|}{ Raman frequency $\left(\mathrm{cm}^{-1}\right)$} & $\mathrm{I}_{\mathrm{D}} / \mathrm{I}_{\mathrm{G}}$ \\
\hline \multirow[t]{2}{*}{ Pristine } & G & 1360 & 0.1 \\
\hline & $\mathrm{D}$ & 1585 & \\
\hline \multirow[t]{2}{*}{ T90 } & $\mathrm{G}$ & 1362 & 0.7 \\
\hline & $\mathrm{D}$ & 1590 & \\
\hline \multirow[t]{2}{*}{ T110 } & G & 1360 & 0.8 \\
\hline & $\mathrm{D}$ & 1585 & \\
\hline \multirow[t]{2}{*}{ T130 } & $\mathrm{G}$ & 1360 & 0.8 \\
\hline & $\mathrm{D}$ & 1583 & \\
\hline \multirow[t]{2}{*}{ T150 } & G & 1360 & 0.7 \\
\hline & $\mathrm{D}$ & 1585 & \\
\hline
\end{tabular}

MWCNTs. Fraczek-Szcypta [36] used $\mathrm{H}_{2} \mathrm{SO}_{4}$ and $\mathrm{HNO}_{3}$ with a volumetric ratio (3:1, respectively) at $60^{\circ} \mathrm{C}$ and $70{ }^{\circ} \mathrm{C}$. The $\mathrm{I}_{\mathrm{D}} / \mathrm{I}_{\mathrm{G}}$ ratio also increased after the acid treatment and is explained as a decrease in crystallinity.

Among the treated MWCNTs the $\mathrm{I}_{\mathrm{D}} / \mathrm{I}_{\mathrm{G}}$ ratios vary, although this difference is small.

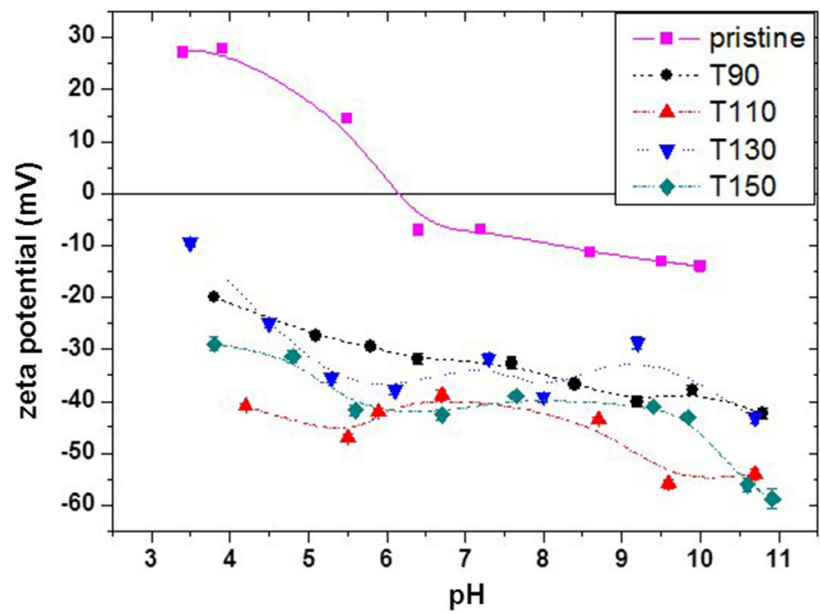

Fig. 6. Zeta potential of treated and pristine MWCNTs as a function of pH.

\subsection{Zeta potential}

Fig. 6 shows the zeta potential as a function of $\mathrm{pH}$ for MWCNT water suspensions. The differences can be directly correlated with the oxidized species on the tube surface and their effect on the suspension behavior.

An increase in the negative charge and also a shift of the isoelectric point to lower $\mathrm{pH}$ can be attributed to the presence of carboxylic groups on the MWCNT surface which turns the nanotubes hydrophilic, as shown in the zeta potential measurement.

The pristine MWCNTs, present its surface positively charged at $\mathrm{pH}$ lower than 6 (isoelectric point) due to the presence of the oxidized species $(\mathrm{OH}-$ and $\mathrm{COOH}-$ groups) identified in the original MWCNTs.

The surface of the MWCNT samples oxidized by $\mathrm{H}_{2} \mathrm{SO}_{4} / \mathrm{HNO}_{3}$ mixture is negatively charged in a wide range of $\mathrm{pH}$ values, which can be explained by two factors: first, the suppression of the diffuse double layer is accompanied by a decrease in the absolute zeta potential; second, the increasing dissociation of the surface groups results in a constant increase [37].

From $\mathrm{pH} 3$ to 6 and from 8 to 11 it was observed that T110 has more negative than others. On the other hand, in the range of 6 to 8 the T150 has the highest zeta (negative) potential and similar to T110.

In the potential heterocoagulation processing of ceramicMWCNT composites, it could be stand that an improved coagulation would be obtained after higher electrostatic charges difference 

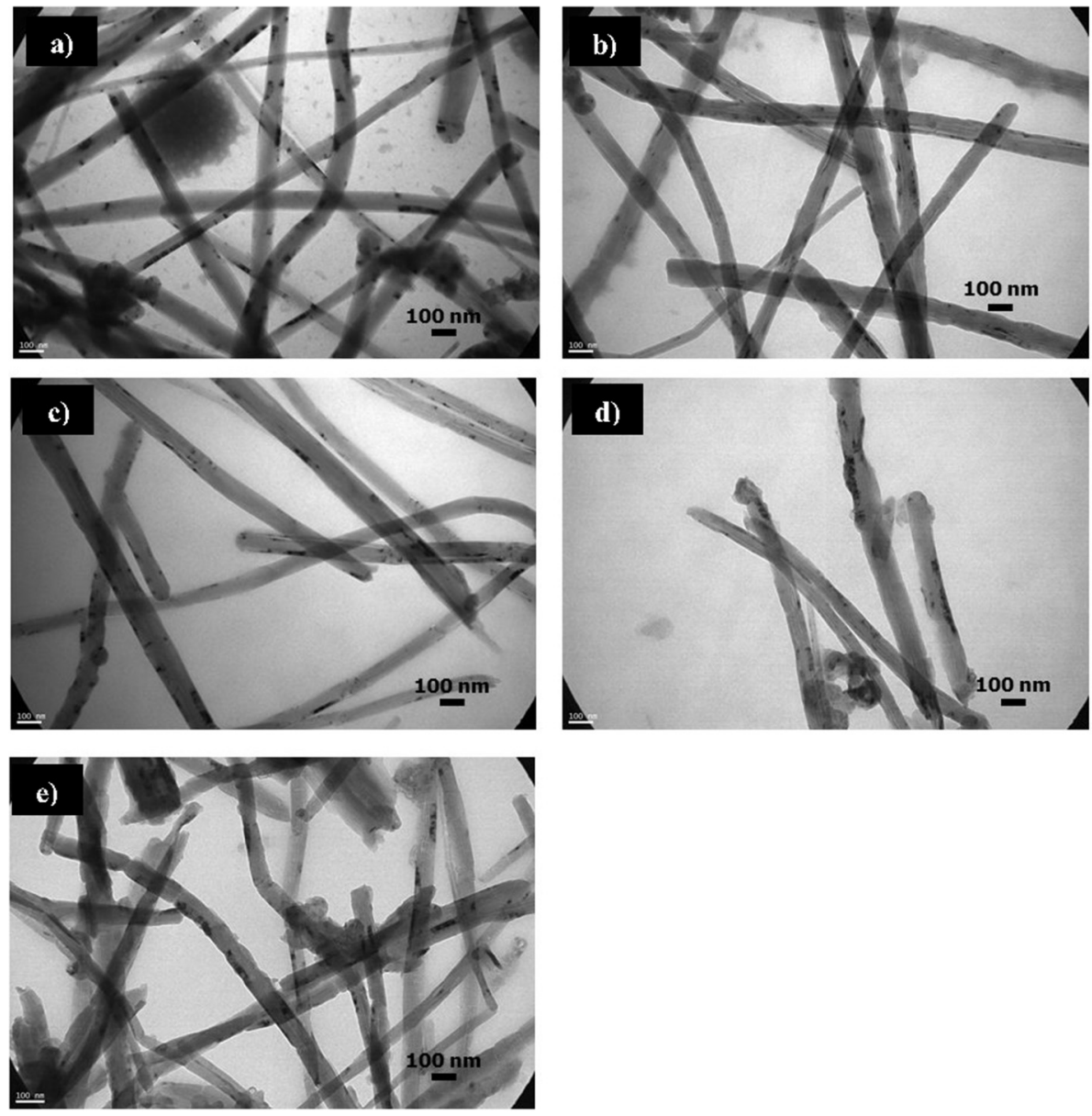

Fig. 7. TEM images of samples (a) pristine (b) T90 (c) T110 (d) T130 (e) T150.

between the two particle types. All the treatment temperatures are suitable for generating the heterocoagulation. It can be noticed that T90 present the minimum zeta potential gap with the ceramic suspension. For these temperatures higher from $90{ }^{\circ} \mathrm{C}$ can be used for this purpose. Taking also in account the risk of manipulating nitric and sulfuric acid at high temperature it is recommended to use acid treatment of CNT at $110^{\circ} \mathrm{C}$. In this case, the ceramic particle $\left(\mathrm{Al}_{2} \mathrm{O}_{3}\right.$ or $\left.\mathrm{ZrO}_{2}\right)$ and the carbon $\mathrm{T} 110$ nanoparticle presumably would present better mixture when coagulated [38], resulting after sintering in composites with more homogeneous mixture and probably better reinforcements mechanisms of the composite.

\subsection{Morphological analysis by TEM}

The morphology of MWCNTs was observed by TEM and is shown in Fig. 7. In Fig.7 a (pristine), it is observed that the tubes have smooth walls, without roughness. Fig. 7b-e correspond to samples T90, T110, T130 and T150 respectively. The larger particles that appear in some figures (mainly in Fig. 7a) are product of the grid used in the measurement. Fig. 7b and c (T90 and T110) show that the nanotube surface is no longer so smooth. The sample treated at $90{ }^{\circ} \mathrm{C}$ has rounded tips similar to that of pristine MWCNTs. When the temperature is raised to $110^{\circ} \mathrm{C}$ it is observed that the tube ends are broken. In this regard, Liu observed that using a mixture of $\mathrm{H}_{2} \mathrm{SO}_{4} / \mathrm{HNO}_{3}$ the tube terminations were opened after treatment, concluding that the carboxyl groups were then produced at the open ends of the tubes [9]. Chen et al. also studied the oxidation of the CNT finding that the oxidation occurs at the end of the tubes and on the sides of the walls [39].
In Fig. $7 \mathrm{~d}$ and $\mathrm{e}$ it is observed that the smooth feature of the pristine MWCNT walls is almost completely lost. Especially, in sample T150 several grooves and folds are present in certain places. Referring to a similar observation, Zhang et al. stated that the acid treatment creates a greater number of oxidation sites, and thus intercalate and exfoliate the graphene structure [40].

Marshall et al. [41] observed a cut-off effect on the single wall CNTs with an acid treatment and ultrasonication at room temperature. From Fig. 7, we cannot assert that the MWCNTs studied in this work treated at different temperatures are cut. The cut-off effect found by Marshall can be attributed to the fact that the CNTs they used are single-walled and that the treatment time spent by that research group was longer than $2 \mathrm{~h}$.

In conclusion, due to the difference between the treated and untreated MWCNT surfaces (roughness, folds and grooves) we can affirm that the sulfonitric treatment at short times generates the oxidation of the nanotubes-resulting in a modification and even deterioration of the MWCNTs surface- and the effect of oxidation increases with the temperature of the treatment.

\section{Conclusions}

The acid treatment of MWCNTs was carried out to study its surface modifications in order to achieve a good dispersion and distribution of the tubes in a ceramic material containing them. It was carried out at different temperatures $\left(90,110,130\right.$ and $\left.150{ }^{\circ} \mathrm{C}\right)$.

The complete characterization of the tubes was performed in order to know and compare the effect of the acid and thermal treatment. 
It was established by XPS and FTIR techniques that there is an increase in the amount of surface oxidized species after the mentioned treatment. By XRD, it was found that at high treatment temperatures ( 130 and $150{ }^{\circ} \mathrm{C}$ ), a contribution of a disorder graphene peak is observed. Through TEM, it was observed that there is deterioration in the carbon nanotubes walls. The increase of oxidized species improves the dispersion of MWCNTs in aqueous solution, favoring the anchoring of the tubes in a possible matrix containing them.

In addition, it was found that the percentage of each of the oxidized species varies with the temperature of the acid treatment. The influence of the acid treatment temperature on the oxidation of the carbon nanotubes was studied by various techniques. They showed that oxidation is a sequential process, and this is seen in the percentage of the oxidized species found in the analyzed samples as well as in the superficial deterioration evidenced in the diminution of the conjugated $\pi$ bonds. One of the mentioned applications of the studied sulfonitric treatment was as pretreatment of the MWCNT for reinforced ceramic composite materials. The heterocoagulation needs a maximum zeta potential gap between the ceramic and the MWCNT surface. All the treatment temperatures are suitable for generating the heterocoagulation. It can be noticed that T90 presents the minimum zeta potential gap with the ceramic suspension. For these temperatures higher from $90^{\circ} \mathrm{C}$ can be used for this purpose. Taking also in account the risk of manipulating nitric and sulfuric acid at high temperature it is recommended to use acid treatment of CNT at $110^{\circ} \mathrm{C}$.

\section{Acknowledgments}

Authors are grateful to Lic. M. Susana Conconi from CETMIC for her help in XRD analysis and collaboration with fruitful discussion. We also acknowledge to Aldo Rubert from INIFTA for his help in XPS analysis. Finally we acknowledge financial support from CONICET (Consejo de Investigaciones Científicas y Tecnológicas) and ANPCyT (Agencia Nacional de Promoción Científica y Tecnológica).

\section{References}

[1] M. Endo, Y.A. Kim, T. Hayashi, Y. Fukai, K. Oshida, M. Terrones, et al., Structural characterization of cup-stacked-type nanofibers with an entirely hollow core Appl. Phys. Lett. 80 (7) (2002) 1267-1269.

[2] M. Endo, Y.A. Kim, T. Hayashi, K. Nishimura, T. Matusita, K. Miyashita, et al., Vapor-grown carbon fibers (VGCFs) - Basic properties and their battery applications, Carbon 39 (9) (2001) 1287-1297.

[3] T.T. Tan, H.S. Sim, S.P. Lau, H.Y. Yang, M. Tanemura, J. Tanaka, X-ray generation using carbon-nanofiber-based flexible field emitters, Appl. Phys. Lett. 88 (10) (2006) 103105.

[4] X.-L. Zhang, Z.-B. Liu, X. Zhao, W.-Y. Zhou, J.-G. Tian, Nonlinear optical properties of hydroxyl groups modified multi-walled carbon nanotubes, Chem. Phys. Lett. 494 (2010) 75-79.

[5] A.L. Martínez-Hernández, C. Velasco-Santos, V.M. Castaño, Carbon nanotubes composites: Processing, grafting and mechanical and thermal properties, Curr. Nanosci. 6 (1) (2010) 12-39.

[6] A. Barinov, O.B. Malcioğlu, S. Fabris, T. Sun, L. Gregoratti, M. Dalmiglio, et al., Initial stages of oxidation on graphitic surfaces: Photoemission study and density functional theory calculations, J. Phys. Chem. C 113 (21) (2009) 90099013.

[7] M.A. Hamon, H. Hu, P. Bhowmik, S. Niyogi, B. Zhao, M.E. Itkis, et al., End- group and defect analysis of soluble single-walled carbon nanotubes, Chem. Phys. Lett. 347 (1-3) (2001) 8-12.

[8] M.A. Hamon, H. Hui, P. Bhowmik, H.M.E. Itkis, R.C. Haddon, Esterfunctionalized soluble single-walled carbon nanotubes, Appl. Phys. A-Mater. 74 (3) (2002) 333-338.

[9] J. Liu, A.G. Rinzler, H. Dai, J.H. Hafner, R. Kelley Bradley, P.J. Boul, et al., Fullerene pipes, Science 280 (5367) (1998) 1253-1256.

[10] W. Zhou, S. Sasaki, A. Kawasaki, Effective control of nanodefects in multiwalled carbon nanotubes by acid treatment, Carbon 78 (2014) 121-129.

[11] F. Ahmadpoor, S.M. Zebarjad, K. Janghorban, Decoration of multi-walled carbon nanotubes with silver nanoparticles and investigation on its colloid stability, Mater. Chem. Phys. 139 (1) (2013) 113-117.

[12] S.C. Tsang, Y.K. Chen, P.J.F. Harris, M.L.H. Green, A simple chemical method of opening and filling carbon nanotubes, Nature 372 (6502) (1994) 159-162.
[13] G. Yamamoto, M. Omori, T. Hashida, H. Kimura, A novel structure for carbon nanotube reinforced alumina composites with improved mechanical properties, Nanotechnology 19 (2008) 7.

[14] S. Gómez, N.M. Rendtorff, E.F. Aglietti, Y. Sakka, G. Suárez, Surface modification of multiwall carbon nanotubes by sulfonitric treatment, Appl. Surf. Sci. 379 (2016) 264-269.

[15] H. Nishikiori, T. Tanigaki, M. Endo, T. Fujii, Quantitative characterization of acidic groups on acid-treated multi-walled carbon nanotubes using 1aminopyrene as a fluorescent probe, Carbon 66 (2014) 560-566.

[16] C. Lu, F. Su, S. Hu, Surface modification of carbon nanotubes for enhancing BTEX adsorption from aqueous solutions, Appl. Surf. Sci. 254 (21) (2008) 7035-7041.

[17] I.D. Rosca, F. Watari, M. Uo, T. Akasaka, Oxidation of multiwalled carbon nanotubes by nitric acid, Carbon 43 (15) (2005) 3124-3131.

[18] T. Saleh, M. Dahmardeh, A. Bsoul, A. Nojeh, K. Takahata, Field-emissionassisted approach to dry micro-electro-discharge machining of carbonnanotube forests, J. Appl. Phys. 110 (10) (2011) 103305.

[19] Y.-S. Li, J.-L. Liao, S.-Y. Wang, W.-H. Chiang, Intercalation-assisted longitudinal unzipping of carbon nanotubes for green and scalable synthesis of grapheme nanoribbons, Sci. Rep-UK 6 (2016) 22755.

[20] B. Herzog, D. Bokern, T. Braun, R. Schlogl, C. Troyer, On the oxidation of graphite: an in-situ XRD-study, Mater. Sci. Forum 166-169 (1994) 517-522.

[21] B.C. Satishkumar, A. Govindaraj, J. Mofokeng, G.N. Subbanna, C.N.R. Rao, Novel experiments with carbon nanotubes: Opening, filling, closing and functionalizing nanotubes, J. Phys. B-At Mol. Opt. 29 (21) (1996) 4925-4934.

[22] W.M. Daoush, S.H. Hong, Synthesis of multi-walled carbon nanotube/silver nanocomposite powders by chemical reduction in aqueous solution, J. Exp. Nanosci. 8 (5) (2013) 578-587.

[23] Y. Zhu, T. Yi, B. Zheng, L. Cao, The interaction of $C_{60}$ fullerene and carbon nanotube with Ar ion beam, Appl. Surf. Sci. 137 (1999) 83-90.

[24] M.A.M. Motchelaho, H. Xiong, M. Moyo, L.L. Jewell, N.J. Coville, Effect of acid treatment on the surface of multiwalled carbon nanotubes prepared from FeCo supported on CaCO3: Correlation with Fischer-Tropsch catalyst activity, J. Mol. Catal. A-Chem. 335 (1-2) (2011) 189-198.

[25] S. Biniak, M. Pakuła, A. Swiatkowski, M. Walczyk, in: A.P. Terzyk, P.A. Gauden, P. Kowalczyk (Eds.), Carbon materials: theory and practice, research signpost, Trivandrum, Kerala, India, 2008, p. 51 (Chapter 5).

[26] S. Boncel, S.W. Pattinson, V. Geiser, M.S.P. Shaffer, K.K.K. Koziol, En route to controlled catalytic CVD synthesis of densely packed and vertically aligned nitrogen-doped carbon nanotube arrays, Beilstein. J. Nanotechnology 5 (1) (2014) 219-233.

[27] J.H. Kaufman, S. Metin, D.D. Saperstein, Symmetry breaking in nitrogen- doped amorphous carbon: infrared observation of the Raman-active $\mathrm{G}$ and D bands, Phys. Rev. B 39 (18) (1989) 13053-13060.

[28] S.H. Lai, Y.L. Chen, L.H. Chan, Y.M. Pan, X.W. Liu, H.C. Shih, The crystalline properties of carbon nitride nanotubes synthesized by electron cyclotron resonance plasma, Thin Solid Films 444 (1-2) (2003) 38-43.

[29] M.R. Wixom, Chemical preparation and shock wave compression of carbon nitride precursors, J. Am. Ceram. Soc. 73 (7) (1990) 1973-1978.

[30] S. Kundu, Y. Wang, W. Xia, M. Muhler, Thermal stability and reducibility of oxygen-containing functional groups on multiwalled carbon nanotube surfaces: a quantitative high-resolution xps and TPD/TPR study, J. Phys. Chem. C. 112 (43) (2008) 16869-16878.

[31] M.S. Dresselhaus, G. Dresselhaus, R. Saito, A. Jorio, Raman spectroscopy of carbon nanotubes, Phys. Rep. 409 (2) (2005) 47-99.

[32] K. Behler, S. Osswald, H. Ye, S. Dimovski, Y. Gogotsi, Effect of thermal treatment on the structure of multi-walled carbon nanotubes, J. Nanopart. Res. 8 (5) (2006) 615-625.

[33] J. Kastner, T. Pichler, H. Kuzmany, S. Curran, W. Blau, D.N. Weldon, et al., Resonance Raman and infrared spectroscopy of carbon nanotubes, Chem. Phys. Lett. $221(1-2)$ (1994) 53-58.

[34] G. Katagiri, H. Ishida, A. Ishitani, Raman spectra of graphite edge planes, Carbon 26 (4) (1988) 565-571.

[35] J. Lu, G Wang, L. Sun, F. Gao, F. Yu, H. Zhou, et al., Direct synthesis and characterization of carbon nanotube films prepared by premixed ethanol flame, in: 3rd international, conference on manufacturing science and engineering, ICMSE 20122012: Xiamen. pp. 569-573.

[36] A. Fraczek-Szczypta, E. Dlugon, A. Weselucha-Birczynska, M. Nocun, M. Blazewicz, Multi walled carbon nanotubes deposited on metal substrate using EPD technique. a spectroscopic study, J. Mol. Struct. 1040 (2013) 238245.

[37] L. Vanyorek, R. Meszaros, S. Barany, Surface and electrosurface characterization of surface-oxidized multi-walled N-doped carbon nanotubes, Colloid Surf. A 448 (1) (2014) 140-146.

[38] M. Estili, A. Kawasaki, An approach to mass-producing individually aluminadecorated multi-walled carbon nanotubes with optimized and controlled compositions, Scripta Mater. 58 (10) (2008) 906-909.

[39] R.J. Chen, Y. Zhang, D. Wang, H. Dai, Noncovalent sidewall functionalization of single-walled carbon nanotubes for protein immobilization, J. Am. Chem. Soc. 123 (16) (2001) 3838-3839.

[40] J. Zhang, H. Zou, Q. Qing, Y. Yang, Q. Li, Z. Liu, et al., Effect of chemical oxidation on the structure of single walled carbon nanotubes, J. Phys. Chem. B 107 (16) (2003) 3712-3718

[41] M.W. Marshall, S. Popa-Nita, J.G. Shapter, Measurement of functionalized carbon nanotube carboxylic acid groups using a simple chemical process, Carbon 44 (7) (2006) 1137-1141. 